\title{
CRAFTMANSHIP DALAM PENCIPTAAN POSTER FILM FIKSI ILMIAH "TENGKORAK"
}

\author{
Yusron Fuadi \\ Program Studi Teknologi Rekayasa Perangkat Lunak \\ Departemen Teknik Elektro dan Informatika, Sekolah Vokasi, Universitas Gadjah Mada \\ yusron.fuadi@ugm.ac.id
}

\begin{abstract}
Science fiction is a rare film genre in Indonesia. Indonesian audience do watches science fiction in cinema, but Indonesian production house seems to be less than eager to make as such. Tengkorak is an independent science fiction designed with all the good intention to break those genre barrier.
\end{abstract}

Film poster is a compulsory byproduct of a feature film. It was made to market the film and to be placed mainly in cinema. The nature of independent production of Tengkorak made it impossible to simply put popular face of a-list Indonesian actors. The inspiration of Tengkorak, which is 1980s science fiction, open up an opportuniy to explore design possibilities, to make it distinctive and memorable.

Keywords: Film poster, digital painting, science fiction.

Relevance to Visual Communication Design Practice: As an alternative method of realisating a commercial film poster thus providing an inspiration and an added value.

\section{LATAR BELAKANG MASALAH}

Penulis tumbuh sebagai pecinta film, khususnya genre fiksi ilmiah. Genre ini seakan melegitimasi apa yang biasanya tidak dimiliki genre lain, yaitu bahwa "semuanya mungkin". Kebebasan secara struktur cerita dan visual seperti pisau bermata dua.

Fiksi ilmiah adalah genre meski tidak diragukan lagi popularitasnya, sangat jarang diproduksi di Indonesia. Genre ini tidak tereksplor seperti halnya drama, komedi, horor atau genre relijius. Jadi pada dasarnya, fiksi ilmiah ditonton tapi tidak diproduksi di Indonesia.

Beberapa film fiksi ilmiah terbaik yang pernah dibuat manusia sebenarnya bercerita tentang manusia itu sendiri, atau respon manusia terhadap sebuah fenomena. Mungkin yang terpikir di benak dari kata fiksi ilmiah adalah seputar alien, laser, robot atau layar sentuh. Star Wars mungkin lebih menggambarkan kehidupan samurai daripada sekedar alien. Blade Runner bukan hanya sekedar cybernetics organism namun sebuah study tentang makna menjadi manusia. District 9 mengeksplor politik apartheid dibalut alien yang terdampar di Bumi. Di Amerika pun, genre fiksi ilmiah masih menjadi underdog, tidak pernah menang piala oscar untuk film terbaik.

\section{FILM FIKSI ILMIAH TENGKORAK}

Film ini diawali dari mimpi personal penulis yang kemudian mendapatkan dukungan dari laboratorium Multimedia D3 Komputer dan Sistem Informasi Sekolah Vokasi UGM dan segenap sivitas Universitas Gadjah Mada.

Film Tengkorak adalah sebuah film hasil produksi sivitas akademik UGM yang telah melalui perjuangan sejak 2014 ini pada 
akhirnya dinyatakan selesai diproduksi dan ditayangkan di layar bioskop Indonesia setelah memperoleh kesempatan diputar dalam 6 festival di tingkat Asia maupun internasional hingga hari ini.

Perjalanan festival Film Tengkorak diawali dari Jogja-NETPAC Asian Film Festival di Yogyakarta pada bulan Desember tahun lalu, diikuti dengan Cinequest International Film Festival di California, USA pada bulan Maret 2018, dan yang terbaru, Balinale International Film Festival di Bali pada akhir bulan September 2018. Berbekal respon masyarakat yang luar biasa dari festival yang telah berjalan tersebut, film pertama Yusron Fuadi ini direncanakan ditayangkan serentak melalui jaringan bioskop nasional pada 18 Oktober 2018 .

Film bergenre science fiction ini dibawakan oleh 3 pemain utama yakni Eka Nusa Pertiwi sebagai Eka, Yusron Fuadi sebagai Yos, dan Guh S Mana sebagai Lt. Jaka, dan didukung beberapa aktor film dan teater Jogja. Di samping itu, terdapat ratusan pemain lain dan kru yang terdiri dari warga masyarakat Gunung Kidul, mahasiswa, maupun Dosen UGM.

Bermodalkan budget yang minimalis, film ini dibuat dengan beberapa dobrakan yang dilakukan oleh kru yang notabene belum memiliki skill mencukupi saat awal film ini dibuat, seperti penggunaan kamera standar cinema, miniatur gedung setinggi 2 meter sebagai practical effect, blue screen sepanjang 500 meter, animasi 3D dan motion capture sebagai komponen visual efek, original soundtrack.

Premis film ini sendiri sebetulnya sangat sederhana. Apa yang akan terjadi pada masyarakat jika kita menemukan kerangka manusia setinggi 1850 meter. Film ini adalah sebuah social studies, bagaimana masyarakat dengan berbagai latar belakang dan tingkat pendidikan akan merespon fenomena tersebut.

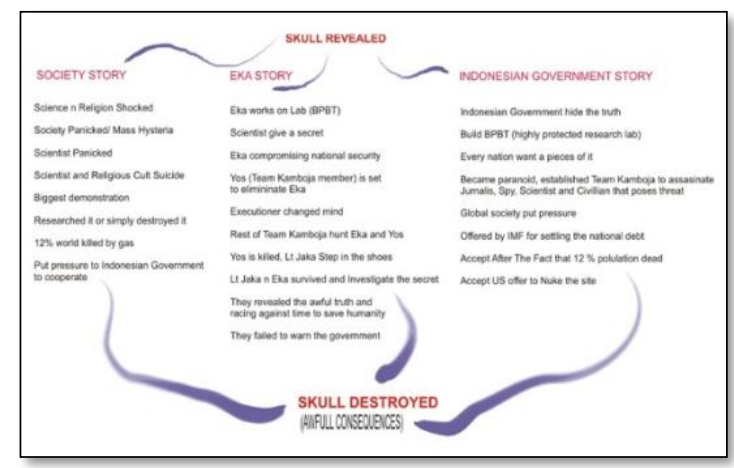

Gambar 1 Tiga Plot Pararel Tengkorak

Plot film Tengkorak bisa disimplikasi menjadi 3 cerita yang pararel, cerita tentang masyarakat, cerita tentang Ani dan cerita tentang pemerintah Indonesia

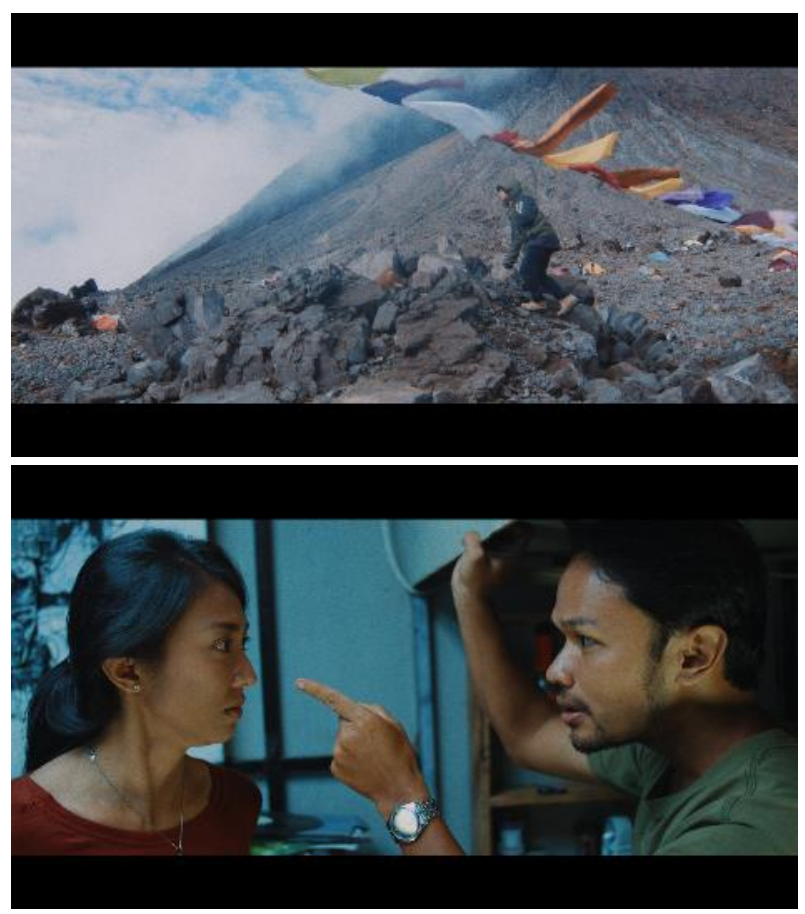



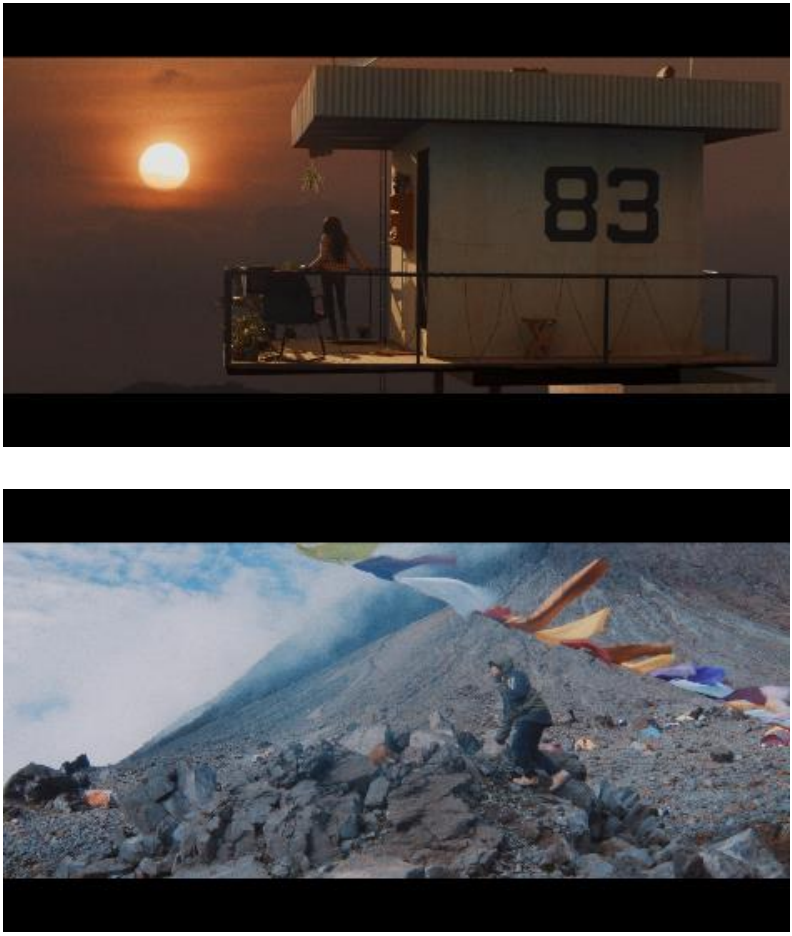

Gambar 2 Stills film Tengkorak

\section{RUMUSAN MASALAH}

Bagaimana merancang sebuah poster film bergenre fiksi imliah Indonesia yang distingtif dan memiliki added value.

\section{TUJUAN DAN MANFAAT}

\section{Tujuan}

Perancangan komunikasi visual bertujuan menyampaikan informasi tentang film Tengkorak sekaligus menarik calon penonton dengan potensi visual yang ditawarkan

\section{Manfaat}

Sebagai sumber inspirasi referensi dan kajian ilmu perancangan desain komunikasi visual, bagi para perancang maupun peneliti

\section{ANALISIS DATA}

What, Apa yang ingin disampaikan?

Poster film bisa dirancang lebih dari sekedar desain sekali pakai namun bisa dieksplor lebih dalam untuk dimaksimalkan potensinya sebagai sebuah artwork. Dengan demikian karya ini akan memenuhi dua fungsi, sebagai karya seni sekaligus memiliki kegunaan praktis (Soedarso, 2006:60)

Where, Di mana perancangan akan diterapkan?

Setiap bioskop komersil selalu memiliki frame frame semi permanen di lorong lorong, dan dinding luar. Ada dua jenis frame, yang pertama bertuliskan COMING SOON dan NOW SHOWING.

When, Kapan perancangan akan dipublikasikan?

Setelah melewati negosiasi yang komplek, film TENGKORAK disetujui jaringan bioskop nasional untuk ditayangkan tanggal 18 Oktober 2018. Tanggal rilis ini akan menjadi bagian dari desain, dan akan diletakkan di bagian bawah poster. Film nasional dan film luar biasanya mendapat treatment yang sedikit berbeda dari segi rentang waktu paska produksi hingga release. Film film seperti Dunkirk atau Star Wars Episode biasanya memiliki poster teaser yang dipasang 8-10 bulan sebelum rilis. Hal ini sangat jarang terjadi di Indonesia, yang biasanya jarak antara paska produksi hingga rilis berkisar 2 hingga 3 bulan. Poster film Indonesia biasanya dipasang 1 hingga 2 bulan sebelum rilis. Dengan skema ini poster film Tengkorak harus sudah jadi minimum 4 bulan sebelum Mei 2018, Poster film pun harus didaftarkan dan lolos Lembaga Sensor Film. 
Who, Siapa target audiens perancangan? Demografi target Film TENGKORAK adalah penonton berusia 17 hingga 35 tahun.

Why, Mengapa perancangan ini penting? Film TENGKORAK menawarkan kebaruan dengan mengusung genre fiksi ilmiah di khasanah perfilman Indonesia.

\section{How, Bagaiman pesan disampaikan?}

Nilai jual utama film Tengkorak adalah originalitas cerita, kebaruan genre di Indonesia dan cara film ini melibatkan penonton. Hal tersebut menajdi brief utama desain poster film ini

\section{POSTER FILM FIKSI ILMIAH TENGKORAK}

Bagi penulis, fim Tengkorak adalah kumpulan referensi,preferensi dan kulminasi pengalaman personal. Independensi produksi berpengaruh pada dua hal, keterbatasan dan kebebasan. Segala aspek produksi film Tengkorak dibatasi oleh kapital namun mendapatkan kebebasan estetis yang mutlak. Tidak ada produser atau studio besar yang mendikte keputusan keputusan aspek produksi. Dan itu adalah sebuah kemewahan (H. Bramantyo, komunikasi personal. 2017, 21 Juni).

Film-film fiksi ilmiah tahun 80an mungkin adalah sumber referensi terbesar penulis dalam berkarya. Poster poster buatan Drew Struzan dalam film Star Wars, Back To The Future, The Things memiliki kualitas craftmanship yang tidak dimiliki generasi setahnya. Tidak ada yang baru di bawah matahari. Akan selalu ada situasi yang mirip, produk yang mirip dan pendekatan yang mirip (Loomis, 1947:220)
Penulis berkesempatan mengeksplor kemungkinan kemungkinan poster yang nantinya bakal dipasang di bioskop. Banyak jalan yang konvesional untuk memasarkan sebuah film lewat poster. Mayoritas poster yang beredar di bioskop gagal mengadirkan desain yang kreatif, bahkan desain yang terkesan template banyak sekali beredar. Kreativitas adalah tentang kepekaan (Hakim, 2007:53) Banyak sekali kemungkinan kemungkinan obyek yang bisa diangkat untuk kebutuhan poster.

1. Karakter utama (konvensional)

2. Balai Penelitian Bukit Tengkorak

3. Demonstrasi

4. Bukit Tengkorak

5. Menara Penjaga

6. Ledakan Nuklir

7. Makhluk yang muncul di akhir film.

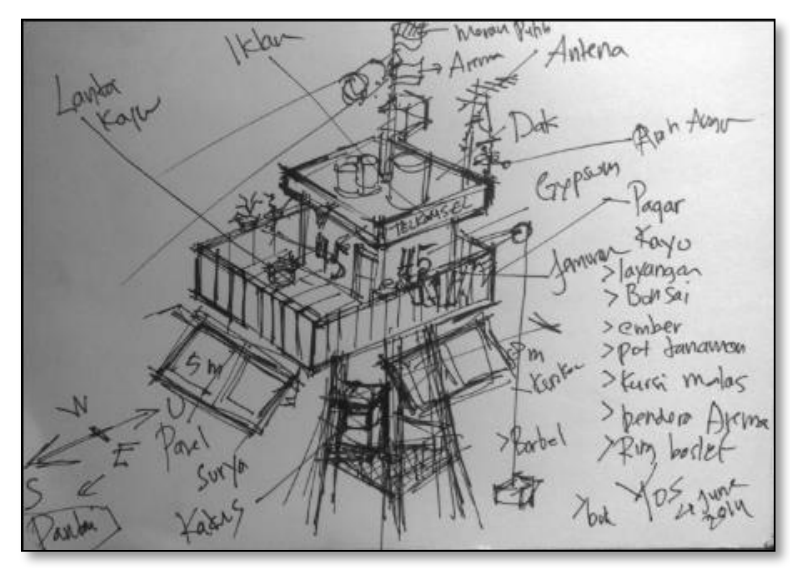

Gambar 3 Sketsa menara penjaga

Penulis mencoba mengeksplor beberapa potensi desain dengan berbagai medium, lewat sketsa manual dan digital. 


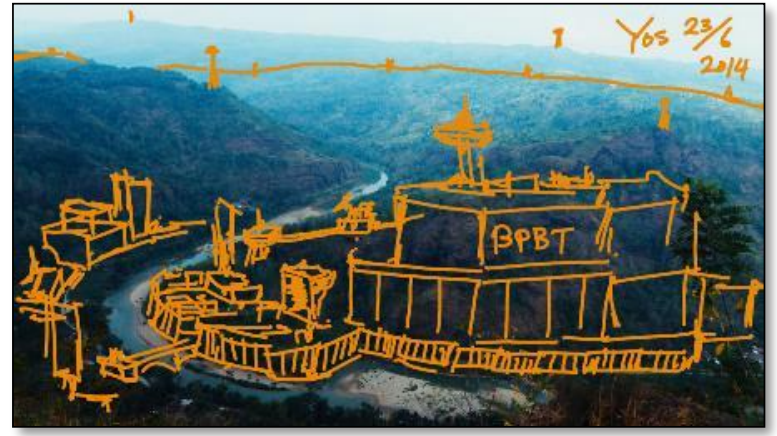

Gambar 4 Ekplorasi BPBT

Balai Penelitian Bukit Tengkorak adalah sebuah departemen bentukan pemerintah khusus untuk melindingi situs Tengkorak itu sendiri. Dalam film diceritakan bahwa Tengkorak raksasa ditemukan di daerah Mangunan Bantul. Kontur lembah yang berkelok sangat potensial untuk diangkat sebagai aspek sinematografi film maupun desain poster.

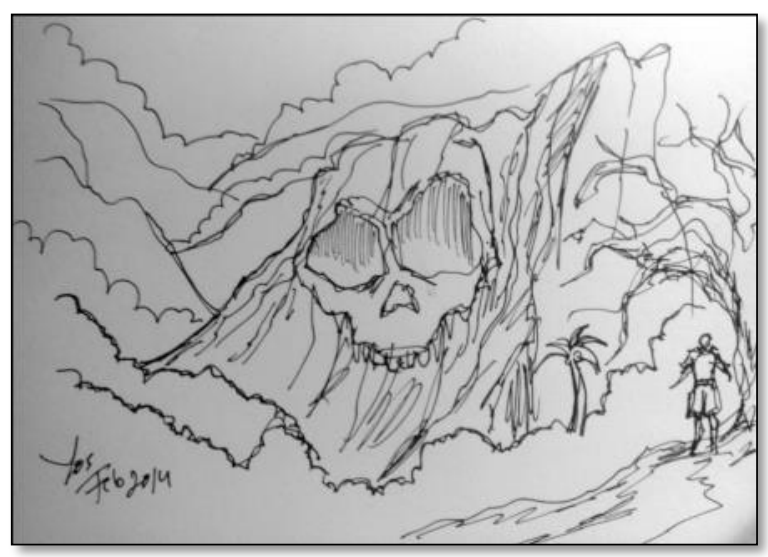

Gambar 5 Sketsa Bukit Tengkorak

Penulis juga telah membuat teaser poster dengan teknik kompositing menggunakan software Adobe Photoshop. Illustrasi adalah seni yang menyertai proses produksi atau pembuatan sebuah gambar, foto atau diagram. Bentuknya bisa berupa naskah, tercetak, terucap atau dalam bentuk eletronik (Fleishmen, 2004: 3)

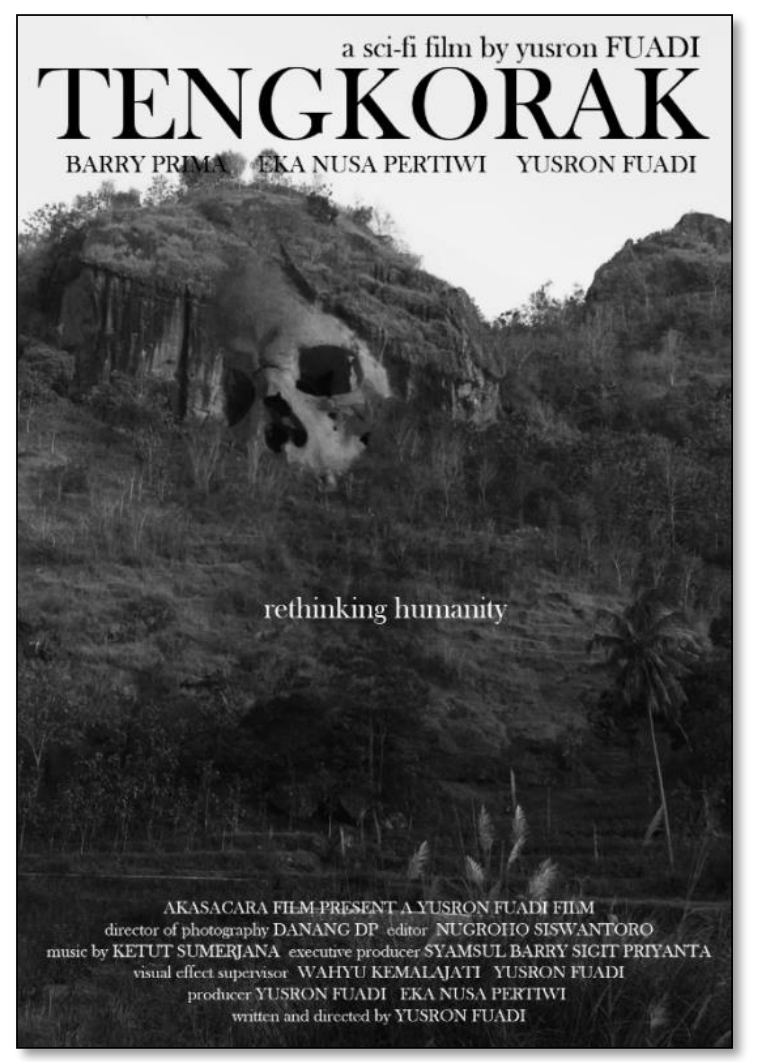

Gambar 6 Teaser Poster Tengkorak

Teaser Poster ini dibuat untuk keperluan publikasi awal dan funding sekaligus preliminary locking location yang dirasa mendukung naratif film.

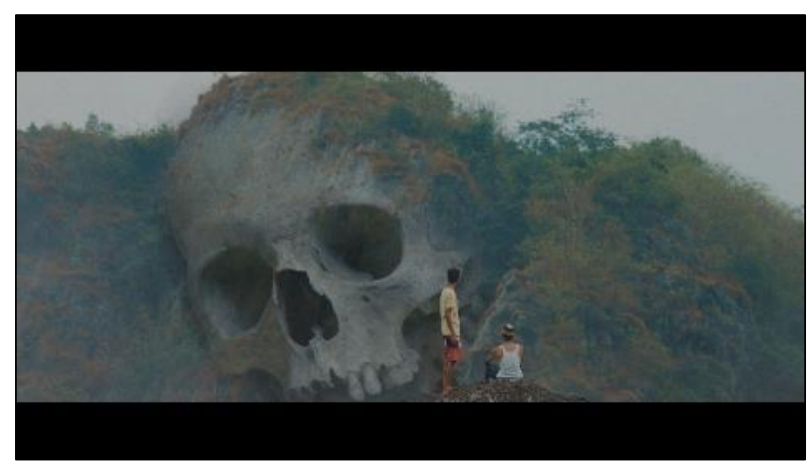

Gambar 7 Stills adegan film Tengkorak

Poster Teaser dan eksplorasi sketsa tersebut berfungsi untuk mengerucutkan ide sekaligus sebagai inspirasi dan starting 
point. Mengutip Neil Lamont, dalam proses kolaboratif ide dilemparkan, dieksplor dan dikembangkan, sambil tetap didorong untuk menembus batas (Kushins, 2016: 11)

Untuk eksekusi finalnya, penulis mencoba mencari commision ilutrastor yang sesuai dengan spirit dari film ini. Pilihan jatuh commission artist dari Bali bernama Ian Permana. Proses komunikasi berjalan intens untuk menyamakan persepsi apa yang ingin dicapai lewat poster

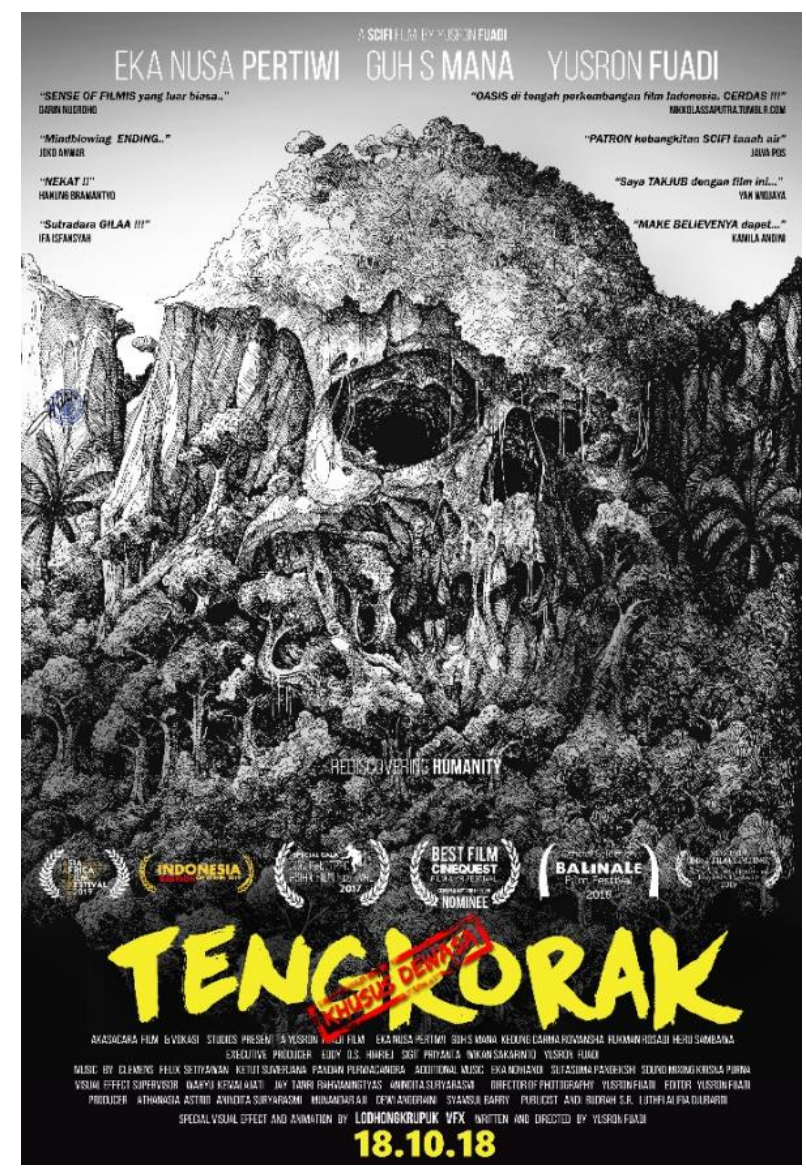

Gambar 8 Poster Final

\section{KESIMPULAN}

Konsep poster film Tengkorak mengusung nilai nilai estetis poster film tahun 1980an. Proses penciptaan poster film TENGKORAK adalah sebuah usaha untuk menghadirkan nilai nilai craftmanship sekaligus upaya menghadirkan romantisme personal penulis terhadap inspirasinya sebagai sutradara, dalam sebuah produk komersil untuk konsumsi masal. Hal itu berhasil dicapai dengan mengkombinasikan metode kompositing modern dengan keterampilan tangan seniman.

\section{DAFTAR PUSTAKA}

[1] Sp, Soedarso. (2006). Trilogi Seni: Penciptaan, Eksistensi dan Kegunaan Seni.. Yogyakarta: BP ISI Yogyakarta.

[2] Loomis, Andrew. (1947). Creative Illustration. London: Titanbooks

[3] Hakim, Budiman. (2007). Ngobrolin Iklan Yuk! . Yogyakarta: Penerbit Galangpress

[4] Fleishman, Michael. (2004). Exploring Illustration. Canada: Thomson Delmar Learning

[5] Kushins, Josh. (2016). The Art of Rogue One : A Star Wars Story. New York: Abrams. 